\title{
Formation of Stable Vaterite with Poly(acrylic acid) by Delayed Addition Method
}

\author{
Kensuke Naka*, Shu-Chen Huang, and Yoshiki Chujo*
}

\section{$\underline{\text { Table of Contents }}$}

Figure s1. X-ray diffraction patterns of the products of (a) run 2, (b) run 3, (c) run 4, (d) run 5 , (e) run 17 in Table 1.

Figure s2. FT-IR spectra of the products of (a) run 2, (b) run 3, (c) run 4, (d) run 5, (e) run 17 in Table 1.

Figure s3. SEM images of the $\mathrm{CaCO}_{3}$ products of (a) run 3 and (c) run 4 with higher magnification images of the products of (b) run 3 and (d) run 4 in Table 1.

Figure s4. TGA thermograph of the products of (a) run $2-$, (b) run $3-$, (c) run $4-$, (d) run $5-$, (e) run $17-$ in Table 1. 


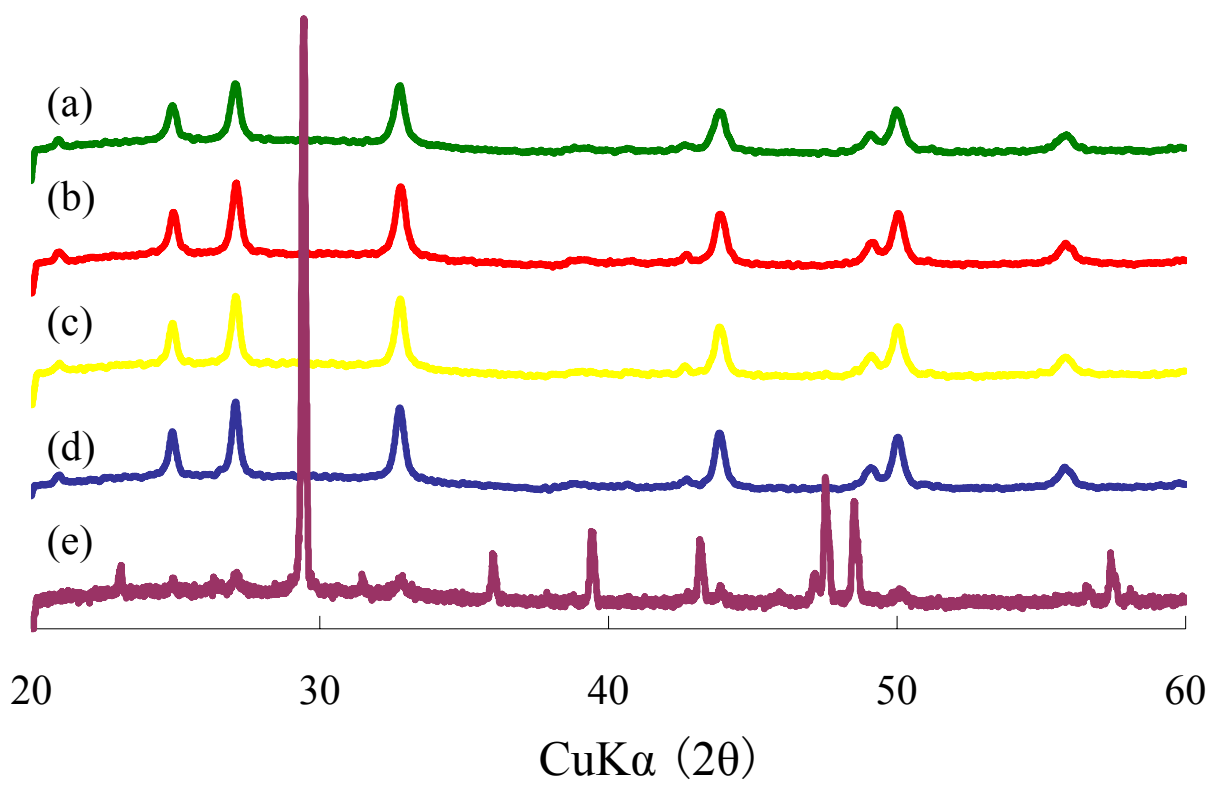

Figure s1. X-ray diffraction patterns of the products of (a) run 2, (b) run 3, (c) run 4, (d) run 5, (e) run 17 in Table 1.

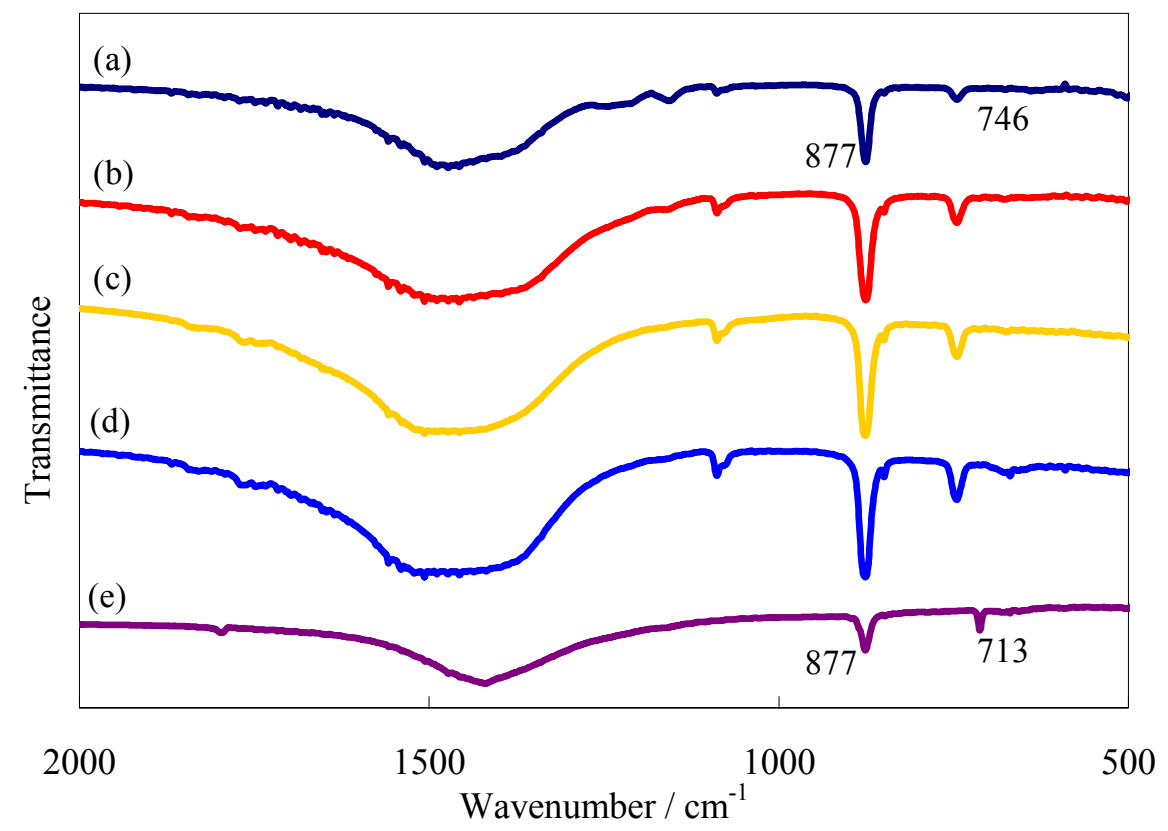

Figure s2. FT-IR spectra of the products of (a) run 2, (b) run 3, (c) run 4, (d) run 5, (e) run 17 in Table 1. 
(a)

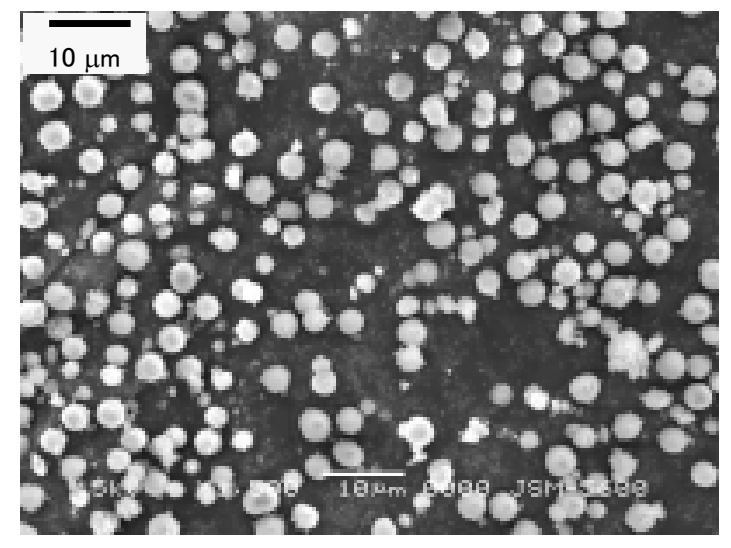

(c)

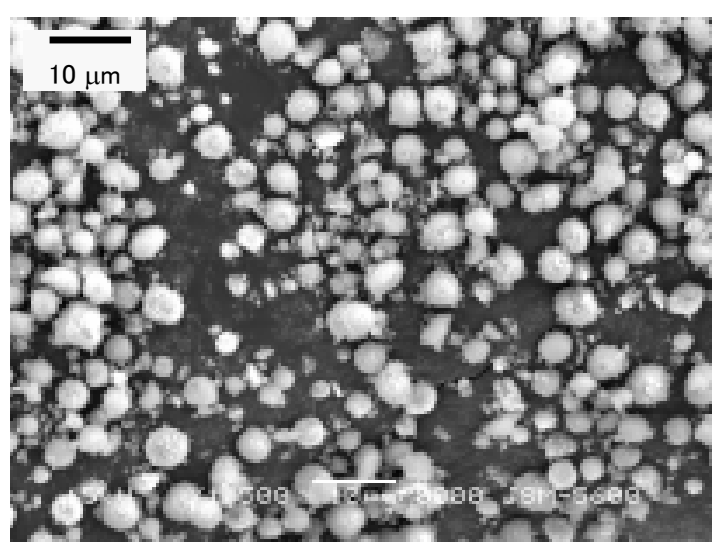

(b)

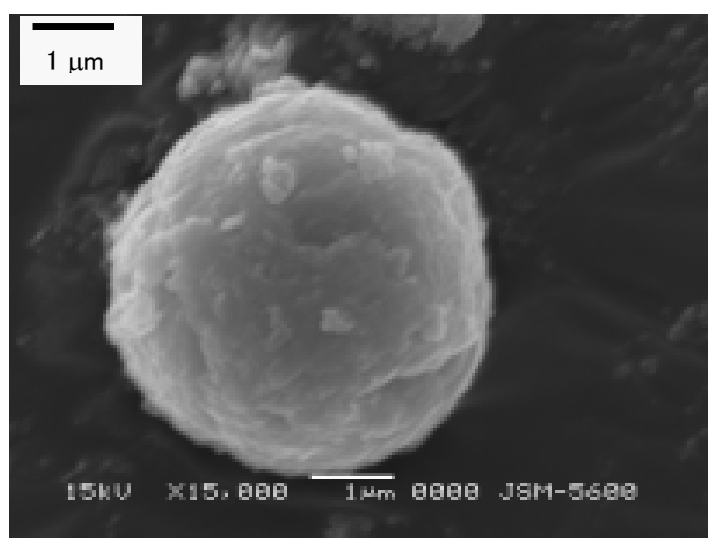

(d)

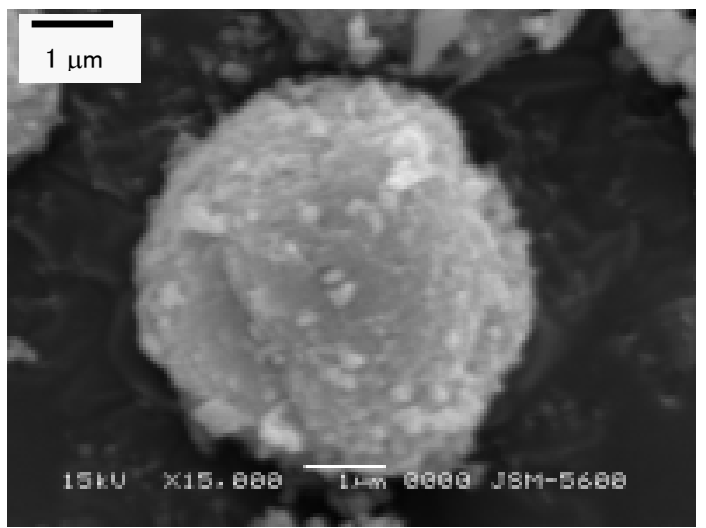

Figure s3. SEM images of the $\mathrm{CaCO}_{3}$ products of (a) run 3 and (c) run 4 with higher magnification images of the products of (b) run 3 and (d) run 4 in Table 1. 


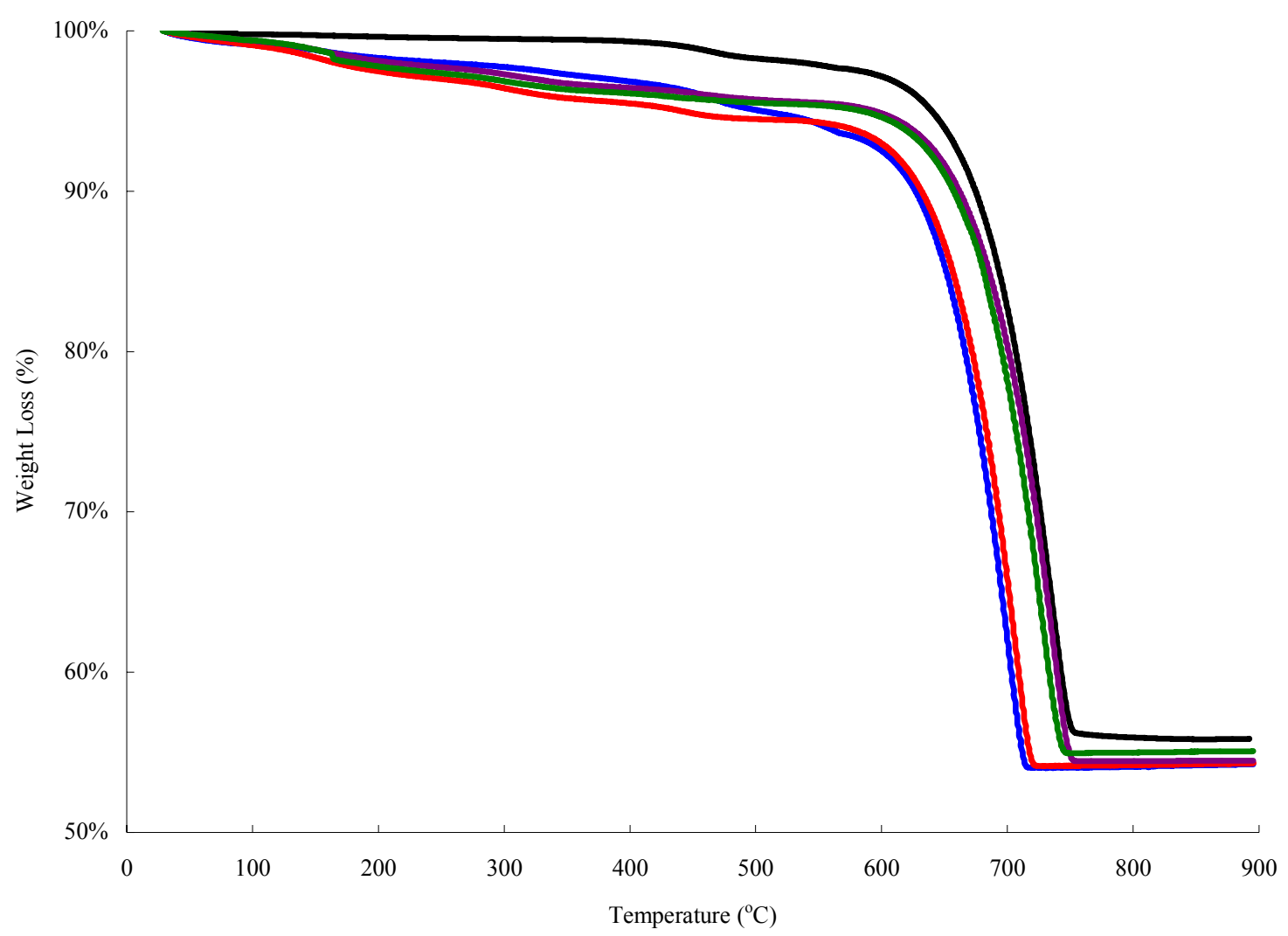

Figure s4. TGA thermograph of the products of (a) run $2-$, (b) run $3-$, (c) run $4-$, (d) run $5-$, (e) run $17-$ in Table 1. 